Pobrane z czasopisma Annales H - Oeconomia http://oeconomia.annales.umcs.pl Data: 26/04/2023 10:17:58

DOI:10.17951/h.2018.52.4.59-71

\begin{tabular}{lcc}
\hline & A N N A L E S \\
UNIVERSITATIS MARIAE CURIE-SKŁODOWSKA \\
LUBLIN - POLONIA \\
SOL. LII, 4 & SECTIO H \\
\hline
\end{tabular}

Uniwersytet Ekonomiczny we Wrocławiu. Wydział Zarządzania

\author{
RADOSŁAW PIETRZYK \\ ORCID ID: http://orcid.org/0000-0002-6583-8424 \\ radoslaw.pietrzyk@ue.wroc.pl \\ PAWEŁ ROKITA \\ ORCID ID: https://orcid.org/0000-0003-2467-5339 \\ pawel.rokita@ue.wroc.pl
}

\title{
Pomiar ryzyka planu finansowego gospodarstwa domowego
}

Risk Measurement of Household Financial Plan

Slowa kluczowe: miary ryzyka; planowanie finansowe; finanse osobiste

Keywords: risk measures; financial planning; personal finance

Kod JEL: D14; D15; D81

\section{Wstęp}

Konstrukcja planu finansowego, obejmującego cały cykl życia gospodarstwa domowego, wymaga uwzględnienia wielu czynników ryzyka, które oddziałują na kształtowanie jego przyszłej ścieżki dochodów i wydatków. Czynniki te mogą mieć bardzo różną naturę oraz zróżnicowany wpływ na strukturę przepływów finansowych [por. Mitchell i in., 2002]. W literaturze brakuje jednak propozycji zintegrowanego pomiaru ryzyka, który umożliwiłby porównanie planów finansowych pod względem łącznego ryzyka. Zintegrowana miara ryzyka powinna nie tyle informować o własnościach statystycznych samych czynników ryzyka, co raczej o tym, na ile możliwe jest to, że plan finansowy nie zostanie zrealizowany z sukcesem z powodu jakiegokolwiek 
niekorzystnego łącznego wpływu tych czynników. Ponieważ poszczególne modele mogą się różnić zarówno rodzajem i liczbą uwzględnionych czynników ryzyka, jak i samą definicją sukcesu bądź porażki planu finansowego, to zintegrowane miary ryzyka planu też mogą być różne.

Procedura optymalizacji planu może prowadzić do znalezienia - w sposób jawny lub niejawny - swego rodzaju kompromisu między poziomem ryzyka a pewną zintegrowaną miarą sukcesu (odpowiadającą poziomowi życia). Uwzględnienie wielu czynników ryzyka w modelu planu finansowego nie zawsze musi oznaczać, że ryzyko jest w nim mierzone. Jeżeli nie jest, optymalizacja planu i tak powinna prowadzić do uzyskania planu będącego kompromisem między przeciwstawnymi dążeniami, a mianowicie do zminimalizowania ryzyka niepowodzenia planu i do maksymalizacji poziomu życia w całym okresie planowania. Jeżeli zaś ryzyko jest mierzone, powinna być $\mathrm{w}$ tym celu zastosowana jego zintegrowana miara, która uwzględniałaby wszystkie czynniki ryzyka włączone do modelu planu finansowego. Wówczas procedura optymalizacyjna powinna prowadzić do podobnego kompromisu, co wspomniany powyżej, ale tym razem byłby on łatwiejszy do zdefiniowania. Chodziłoby bowiem o kompromis między dążeniem do zminimalizowania wartości zintegrowanej miary ryzyka (tym razem zadanej w jawny sposób) i maksymalizacji zintegrowanej miary sukcesu. Takie podejście upodabnia problem optymalizacji planu finansowego do zadania optymalizacji portfela inwestycyjnego w klasycznym modelu Markowitza [1959]. Przy czym problem optymalizacji planu pozostaje znacznie bardziej skomplikowany, gdyż za miarę ryzyka raczej nie można przyjąć po prostu odchylenia standardowego jakiejś zmiennej losowej, a za miarę sukcesu nie można obrać wartości oczekiwanej tej zmiennej. Nie jest nawet oczywiste, co miałoby być tą zmienną, ile powinna mieć wymiarów ani jaki mogłaby mieć rozkład. W tym względzie rozważania zaprezentowane w niniejszym artykule opierają się na modelu zaproponowanym przez Jajugę i współpracowników [2015] oraz Pietrzyka i Rokitę [2016b]. Model ten jest jednak tylko jedną z możliwych propozycji, w której szczególnie ważną rolę odgrywa struktura terminowa skumulowanego przepływu pieniężnego netto (skumulowanej nadwyżki) gospodarstwa domowego. W oparciu o przewidywania właśnie co do przyszłej struktury terminowej skumulowanej nadwyżki budowane są w nim miary ryzyka planu.

$\mathrm{O}$ ile dotychczas nie został rozwiązany problem zintegrowanej miary ryzyka planu finansowego, o tyle podejścia w ogóle uwzględniające różne rodzaje ryzyka w planowaniu finansowym mają bogatą literaturę. Model cyklu życia Yaari'ego [1965] uwzględniał jeszcze tylko jeden czynnik ryzyka, wynikający ze stochastycznego charakteru procesu przeżycia. Ponieważ model ten dotyczył jednej osoby, a nie całego gospodarstwa domowego, był to proces jednowymiarowy. Późniejsze badania często stanowiły modyfikację lub rozszerzenie podejścia Yaari'ego. Poza stochastyczną naturą procesu przeżycia zaczęto uwzględniać również inne czynniki ryzyka, jak np. stopy zwrotu z aktywów finansowych [Merton, 1971; Richard, 1975; Bodie $\mathrm{i}$ in., 2004], przychody z pracy [Geyer, Hanke, Weissensteiner, 2009], stan zdrowia [Scholz, Seshadri, 2010]. Oprócz dodatkowych czynników ryzyka modyfikacje 
uwzględniają też przypadek dwóch osób - pary prowadzącej wspólne gospodarstwo domowe [por. Brown, Poterba, 2000; Hurd, 1999; Kotlikoff, Spivak, 1981].

Podejścia do planowania finansowego uwzględniające czynniki ryzyka nie obejmowały jednak dotąd żadnego sposobu pomiaru łącznego ryzyka niezrealizowania planu (np. przejawiającego się w braku możliwości zrealizowania celów finansowych lub w nieosiągnięciu pożądanego poziomu konsumpcji w którymkolwiek momencie w całym okresie życia). Tymczasem ryzyko to może być mierzone. Jego pomiar może dawać gospodarstwom domowym narzędzie m.in. do oceny prawdopodobieństwa, że nie osiągną zakładanych celów, jeżeli postanowią wdrożyć konkretny plan i realizować go przez całe życie.

\section{Ryzyko w planie finansowym gospodarstwa domowego}

Plan finansowy gospodarstwa domowego może uwzględniać wiele rodzajów i czynników ryzyka. Istnieje wiele możliwych podziałów i klasyfikacji ze względu na różne kryteria. Dyskusja na ten temat została przeprowadzona m.in. przez Jajugę i współpracowników [2015]. Jedną z możliwości jest podział dostosowany do sposobu uwzględniania czynników ryzyka w przepływach finansowych gospodarstwa domowego. Uwzględnia on siedem rodzajów ryzyka:

- ryzyko czasu życia (ryzyko długowieczności i przedwczesnej śmierci),

- ryzyko inwestowania i finansowania,

- ryzyko przychodów,

- ryzyko zdarzeń (zdarzeń ubezpieczalnych),

- ryzyko realizacji celów,

- ryzyko operacyjne planu (w szczególności ryzyko implementacji planu),

- ryzyko modelu.

Wymienione rodzaje ryzyka są bardzo zróżnicowane (różne zmienne ryzyka, różne czynniki ryzyka wpływające na te zmienne oraz różne własności statystyczne czynników ryzyka). Występowanie wielu czynników ryzyka o bardzo różnej naturze, mających wpływ na powodzenie całego planu finansowego, sprawia, że redukcja poszczególnych czynników nie musi wpływać na redukcję ryzyka całego planu. Stanowi to główny powód poszukiwania miar ryzyka, które w sposób kompleksowy mierzyłyby całościowe ryzyko, pozwalając na zarządzanie nim w sposób zintegrowany. Nie mogą być do tego wykorzystane miary znane z przedsiębiorstw i instytucji finansowych, gdyż specyfika funkcjonowania gospodarstwa domowego znacznie się od nich różni.

W większości modeli ryzyka zdefiniowane są zmienna ryzyka oraz poziom odniesienia. Zmienna ryzyka to zmienna losowa, której wartość może być interpretowana jako miara sukcesu (lub niepowodzenia) po podjęciu ryzykownej decyzji. W klasycznym podejściu do podejmowania decyzji jest to wypłata. W przypadku instytucji finansowych jest to najczęściej wartość (np. portfela inwestycyjnego lub 
całej instytucji). Z kolei poziomem odniesienia (benchmarkiem) może być oczekiwana wartość zmiennej ryzyka lub jakaś jej inna ustalona wartość (np. pożądana lub planowana). Jak zatem może wyglądać taka zmienna ryzyka i jej poziom odniesienia w przypadku planowania finansowego dla gospodarstw domowych?

Propozycja przedstawiona w niniejszym artykule opiera się na skumulowanym przepływie pieniężnym netto jako zmiennej losowej. Przy tak ogólnym sformułowaniu zmiennej ryzyka nie da się narzucić konkretnego benchmarku, będzie on bowiem zależał od koncepcji danej zintegrowanej miary ryzyka, ta zaś zależeć będzie od tego, jakiej informacji na temat ryzyka oczekuje gospodarstwo domowe tworzące swój plan finansowy. Dlatego poziom odniesienia jest definiowany dla poszczególnych miar indywidualnie. Podstawowym problemem na tym etapie jest sformułowanie pewnych postulatów i właściwości, które powinny być spełniane przez miary, aby odpowiadały one założonemu celowi. Co więcej, charakter problemu jest taki, że należy uwzględnić zachowanie skumulowanych przepływów pieniężnych netto w całym okresie życia gospodarstwa domowego. Miara ryzyka powinna więc obejmować całą strukturę terminową skumulowanych przepływów pieniężnych netto i oczywiście musi to robić dla różnych scenariuszy przyszłości.

\section{Pomiar ryzyka - postulaty}

Konstrukcja miar ryzyka powinna odpowiadać celom ich tworzenia. Miary powinny również posiadać pewne właściwości, które są przyjęte w literaturze naukowej. W 1999 r. sformułowano pojęcie koherentnej miary ryzyka [Artzner i in., 1999]. Później zostało ono rozszerzone i sformułowano pojęcie wypukłej miary ryzyka [Föllmer, Schied, 2002]. Logiczna spójność i prosta interpretacja finansowa koncepcji wypukłej miary ryzyka sprawia, że jest ona atrakcyjna zarówno dla teoretyków, jak i praktyków świata finansów. Niestety, nie ma bezpośredniej implementacji tego podejścia w planie finansowym gospodarstw domowych obejmujących cały okres ich życia. Wynika to z faktu, że realizacja zmiennej ryzyka w gospodarstwach domowych jest rzadko rozumiana jako utrata wartości aktywów. Może to być w miarę dobra interpretacja dla niektórych aspektów ryzyka gospodarstw domowych, ale nie może dotyczyć całego, zintegrowanego planu finansowego.

Po raz pierwszy próbę dostosowania koncepcji miary ryzyka do potrzeb planowania finansowego w cyklu życia gospodarstwa domowego podjęto w $2016 \mathrm{r}$. [Pietrzyk, Rokita, 2016a]. Sformułowano wówczas listę wymagań, jakie powinny być spełnione przez zintegrowaną miarę ryzyka dla planu finansowego. Na tym etapie badań możliwe jest sformułowanie siedmiu cech, które powinna posiadać taka miara, z zastrzeżeniem, że nie wszystkie muszą być spełnione przez wszystkie miary. Jest tak dlatego, że podejścia do samego pomiaru mogą się różnić, a miary - uzupełniać.

Postulaty zostały sformułowane dla zintegrowanej miary ryzyka planu finansowego dwuosobowego gospodarstwa domowego. Co istotne, model dwuosobowego 
gospodarstwa domowego tam wykorzystany może być łatwo rozszerzony na większą liczbę osób. Postulaty są następujące:

Postulat 1 (subaddytywność). Wartość miary ryzyka dla planu finansowego gospodarstwa domowego dwuosobowego jest mniejsza lub równa sumie wartości tej miary dla dwóch planów, stworzonych odrębnie dla dwóch członków tego gospodarstwa domowego (przy założeniu, że inne warunki pozostają niezmienione).

Postulat 2 (przechodniość). Jeżeli plan A nie jest bardziej ryzykowny niż $\mathrm{B}$ i plan B nie jest bardziej ryzykowny niż C, to plan A nie jest również bardziej ryzykowny niż C.

Postulat 3. Miara powinna odzwierciedlać wielkość ewentualnego niedoboru.

Postulat 4. Miara powinna być wrażliwa na fazę cyklu życia gospodarstwa domowego, w którym wystąpi potencjalny niedobór.

Postulat 5. Miara powinna odzwierciedlać długość okresu (okresów), w którym w gospodarstwie domowym wystąpią potencjalne niedobory.

Postulat 6. Miara powinna zawierać informacje o prawdopodobieństwie wystąpienia niedoborów (np. liczba scenariuszy z niedoborami i prawdopodobieństwa wystąpienia tych scenariuszy).

Postulat 7. Miara powinna być zgodna z interpretacją, że scenariusz, który kończy się nadwyżką (ponad benchmarkiem), jest lepszy niż scenariusz kończący się niedoborem (poniżej benchmarku).

Należy jeszcze sformułować postulat odnoszący się do optymalizacji planu. Procedura optymalizacji planu musi być zgodna z modelem preferencji gospodarstw domowych i miarą ryzyka zastosowaną w tej optymalizacji:

Postulat 8 . Im wyższa awersja do ryzyka deklarowana przez członków gospodarstwa domowego, tym mniej ryzykowny optymalny plan.

Odwrotna sytuacja nie zachodzi, ponieważ mniejsza awersja do ryzyka nie powinna automatycznie oznaczać bardziej ryzykownego wyniku optymalizacji (wynikowy plan może być bardziej ryzykowny, ale tylko wtedy, gdy oczekiwana wartość miary sukcesu dla tego bardziej ryzykownego wyniku będzie wyższa niż w przypadku mniej ryzykownego).

Postulat 1 mówi, że podział ryzyka w gospodarstwie domowym (uzyskany dzięki wewnętrznym transferom kapitału) powoduje zmniejszenie ryzyka w planie finansowym lub przynajmniej go nie zwiększa. Postulat 2 gwarantuje podstawową logiczną spójność. Postulaty 3-6, traktowane razem, nakładają wymóg, aby miara analizowała cały proces skumulowanych przepływów pieniężnych netto, uwzględniała kształty jego trajektorii we wszystkich rozważanych scenariuszach, rozpoznawała niedobory jako przypadki realizacji ryzyka oraz zależała od czasu ich występowania i prawdopodobieństwa wystąpienia scenariusza powodującego niedobór. Postulat 7 mówi o tym, że miara ryzyka powinna odzwierciedlać także wartość pozostawionego majątku (spadku). Oznacza to w przybliżeniu, że takie plany, dla których bardziej prawdopodobny jest brak pozostawionego majątku (lub majątku o wartości poniżej pewnego poziomu odniesienia), są bardziej ryzykowne niż te, które kończą się nadwyżką finansową. 


\section{Miary ryzyka}

Bazowy model planu finansowego gospodarstw domowych opiera się na przepływach pieniężnych, a jednym z głównych sposobów wyrażenia rezultatu optymalizacji planu jest struktura terminowa skumulowanych przepływów pieniężnych netto gospodarstwa domowego (dokładniej - wiązka struktur terminowych odpowiadających różnym analizowanym scenariuszom). Dlatego zintegrowana miara ryzyka powinna być dostosowana do tego sposobu opisu sytuacji finansowej gospodarstw domowych. Charakter problemu powoduje negatywną koncepcję ryzyka, co z kolei implikuje wybór środków zmniejszających ryzyko. W artykule zaproponowano następujące trzy miary ryzyka: Residual Wealth at Risk (RWaR), Lifetime Cumulated Net Cash Flow at Risk (LCNCFaR, LCaR) i Household Default Probability (HDP).

Ze względu na to, że modele planowania finansowego zaproponowane przez Pietrzyka i Rokitę [2015a, 2015b] są dyskretne i oparte na skończonej liczbie scenariuszy przeżycia, oszacowanie miary jest również wykonywane dla siatki dyskretnych scenariuszy wielowariantowych, należących do hipersześcianu utworzonego przez przedziały ufności dla wszystkich rozważanych czynników ryzyka.

\subsection{Residual Wealth at Risk (RWaR)}

Miara ta wywodzi się wprost $\mathrm{z}$ miary Cash Flow at Risk (CFaR). W tym przypadku zmienną losową jest skumulowany przepływ pieniężny w końcowym momencie istnienia gospodarstwa domowego. Moment ten jest zmienny i zależy od rozpatrywanego scenariusza. Kalkulacja tej miary może być przedstawiona w następujących etapach:

1. W każdym ze scenariuszy szacowany jest poziom odchylenia skumulowanego przepływu finansowego netto (lub końcowej wartości majątku) od zdefiniowanej wartości oczekiwanej.

2. Określany jest lewy kwantyl odchyleń odpowiadający ustalonemu poziomowi tolerancji 1-q (małej wartości poziomu istotności $q$ ). Zatem miara ryzyka (RWaR) może być opisana formułą:

$$
P\left(C S p_{T_{B}} \leq X C S p_{T_{B}}-R W a R\right)=q
$$

gdzie:

$X C S p_{T_{B}}$ - poziom odniesienia (benchmark) dla skumulowanego przepływu pieniężnego netto $\mathrm{W}$ końcowym momencie istnienia gospodarstwa domowego

$C S p_{T_{B}}$ - skumulowany przepływ pieniężny netto w końcowym momencie istnienia gospodarstwa domowego

RWaR - miara Residual Wealth at Risk

$q$ - poziom istotności miary RWaR 


\subsection{Lifetime Cumulated Net Cash Flow at Risk (LCNCFaR, LCaR)}

Drugą z miar jest Lifetime Cumulated Net Cash Flow at Risk. Została zaproponowana, aby w większym stopniu uwzględnić zagrożenia występujące w całym cyklu życia, a nie tylko w ostatnim momencie funkcjonowania gospodarstwa domowego. W koncepcji tej zakłada się, że zarówno moment wystąpienia niedoboru, jak i długość okresu, w którym niedobór ten występuje, są istotne i powinny być uwzględnione w mierze ryzyka. Jeżeli w którymkolwiek z rozpatrywanych scenariuszy wystąpi skumulowany niedobór, sytuacja taka jest traktowana jako realizacja ryzyka.

Miara LCaR jest konstruowana w następujących etapach:

- w każdym ze scenariuszy wszystkie skumulowane niedobory są sumowane,

- ze wszystkich scenariuszy wyznaczany jest kwantyl sum skumulowanych niedoborów w scenariuszach w oparciu o zdefiniowany poziom istotności $q$ o niewielkiej wartości.

Miara ta może być formalnie zdefiniowana za pomocą wyrażenia (2):

$$
P(C C S h \leq-L C a R)=q
$$

gdzie:

CCSh - suma skumulowanych niedoborów

$q$ - poziom istotności miary LCaR

Miara Lifetime Cumulated Net Cash Flow at Risk jest kwantylem sum skumulowanych niedoborów występujących w całym cyklu życia gospodarstwa domowego pomnożonym przez (-1). Suma skumulowanych niedoborów (CCSh) jest zdefiniowana dla każdego scenariusza $Z$. Skumulowane niedobory można zdefiniować zgodnie z wzorem (3). Suma skumulowanych niedoborów jest z kolei obliczana dla wszystkich okresów w cyklu życia gospodarstwa domowego (od momentu początku planu aż do jego końca w momencie $T_{B}^{*}$ dla danego scenariusza $Z^{*}$ ) zgodnie z formułą (4).

$$
\begin{aligned}
& C S h_{t}=\left\{\begin{array}{ccc}
C S p_{t} & \text { if } & C S p_{t}<0 \\
0 & \text { if } & C S p_{t} \geq 0
\end{array}\right. \\
& C \operatorname{CSh}^{\left(\mathbf{z}^{*}\right)}=\left\{\sum_{t=1}^{T_{B}^{*}} \operatorname{CSh}_{t}\left(\mathbf{z}^{*}\right)\right.
\end{aligned}
$$

gdzie:

$C S h_{t}^{\left(\mathbf{z}^{*}\right)}$ - skumulowany niedobór w momencie $t$ w scenariuszu $Z^{*}$

$C C S h^{\left(\mathbf{z}^{*}\right)}$ - suma skumulowanych niedoborów od momentu początku planu do momentu końca istnienia gospodarstwa domowego w scenariuszu $Z^{*}$ 
Zaproponowana miara obejmuje zarówno wielkość, jak i długość występowania niedoborów, ale wprost nie uwzględnia możliwości pokrycia skumulowanego niedoboru w przyszłości lub jej braku. Nie generuje zatem sygnału o potencjalnej możliwości niewypłacalności gospodarstwa domowego.

\subsection{Household Default Probability (HDP)}

Trzecią propozycją jest miara Household Default Probability (Prawdopodobieństwo Bankructwa Gospodarstwa Domowego). Bierze ona pod uwagę jedynie takie skumulowane niedobory, które przekraczają ustalony próg bankructwa, poniżej którego gospodarstwo domowe nie byłoby zdolne do regulowania swoich zobowiązań, a co z tego wynika dochodziłoby do dalszego zadłużania. Ważna rolę pełni tu próg bankructwa, który jest wyznaczany dla każdego okresu w cyklu życia gospodarstwa domowego. Może on być utożsamiany ze zdolnością kredytową w danym momencie.

Miara jest konstruowana w czterech krokach:

- w momencie startu planu ( $\left.t_{0}\right)$ ustalany jest próg bankructwa (np. zdolność kredytowa gospodarstwa domowego), a następnie jest określana wartość progu (zależna od sytuacji finansowej) w kolejnych okresach, aż do momentu końca gospodarstwa domowego,

- dokonywana jest identyfikacja scenariuszy bankructwa - scenariuszy, w których co najmniej w jednym momencie poziom skumulowanego niedoboru przekroczy próg bankructwa,

- określane jest prawdopodobieństwo scenariuszy bankructwa,

- prawdopodobieństwa scenariuszy bankructwa są sumowane w celu uzyskania łącznego prawdopodobieństwa bankructwa gospodarstwa domowego.

Definiując miarę, oznaczmy przez $\mathrm{Z}$ wielowymiarową zmienną losową zwaną „scenariuszem”, a jej realizację - symbolem Z $Z^{*}$. Scenariusz jest wektorem czynników ryzyka uwzględnianych $\mathrm{w}$ modelu planu finansowego i może być określony jako: $\mathbf{Z}=\left[X_{1}, X_{2}, \ldots, X_{n}\right]$, gdzie zmienne $X_{i}$ są zmiennymi losowymi opisującymi czynniki ryzyka.

Scenariusz bankructwa może być zdefiniowany jako taki, w którym skumulowany niedobór przekroczył poziom progu bankructwa. Można go formalnie zdefiniować za pomocą wzoru (5):

$$
\mathbf{T}^{*}=\mathbf{Z}^{*}: \underset{t=1, \ldots, T_{B}^{*}}{\exists} \operatorname{CSp}_{t}^{\left(\mathbf{z}^{*}\right)}<D T h_{t}^{\left(\mathbf{z}^{*}\right)}
$$

gdzie:

$C S p_{t}^{\left(\mathbf{Z}^{*}\right)}$-skumulowany przepływ pieniężny netto (skumulowana nadwyżka finansowa) $\mathrm{w}$ momencie $t \mathrm{w}$ scenariuszu $\mathrm{Z}^{*}$

$T_{B}^{*}$ - moment końca gospodarstwa domowego w scenariuszu $Z^{*}$, który jest określany jako moment śmierci członka gospodarstwa domowego żyjącego dłużej w tym 
scenariuszu $\left(T_{B}^{*}=\max \left\{D_{1}^{*}, D_{2}^{*}\right\}\right.$, gdzie $D_{1}^{*}, D_{2}^{*}-$ momenty śmierci odpowiednio osoby 1 i 2)

$$
D T h_{t}^{\left(\mathbf{z}^{*}\right)} \text { - próg bankructwa w momencie } t \mathrm{w} \text { scenariuszu } \mathrm{Z}^{*}
$$

Prawdopodobieństwa bankructwa w poszczególnych scenariuszach są zatem określane zgodnie z formułą (6):

$$
p_{\mathbf{T}_{i}^{*}}=\left\{\begin{array}{ccc}
p_{\mathbf{z}_{i}^{*}} & \text { if } & \underset{t=1, \ldots, T_{B}^{*}}{\exists} \operatorname{CSp} p_{t}^{\left(\mathbf{z}_{i}^{*}\right)}<D T h_{t}^{\left(\mathbf{z}_{i}^{*}\right)} \\
0 & \text { if } & \underset{t=1, \ldots, T_{B}^{*}}{\forall} \operatorname{CSp} p_{t}^{\left(\mathbf{z}_{i}^{*}\right)} \geq D T h_{t}^{\left(\mathbf{z}_{i}^{*}\right)}
\end{array}\right.
$$

gdzie:

$p_{\mathbf{Z}_{i}^{*}}-$ prawdopodobieństwo scenariusza $i$ ( $i$-tej realizacji zmiennej losowej $\mathrm{Z}$ )

Miara Household Default Probability ostatecznie jest sumą prawdopodobieństw scenariuszy bankructwa daną wzorem (7):

$$
H D P=\sum_{i=1}^{n} p_{\mathbf{T}_{i}^{*}}
$$

Taka konstrukcja miary HDP sprawia, że jest to miara stosunkowo prosta do kalkulacji i jednocześnie pozwalająca na porównanie różnych planów finansowych (o różnych poziomach przepływów finansowych i różnych oczekiwanych długościach). Zaletą jest również jej łatwa interpretacja, co stwarza szansę, że będzie zrozumiała dla potencjalnych użytkowników, którymi są członkowie gospodarstw domowych i ich doradcy finansowi.

Do konstrukcji tej miary potrzebne jest zdefiniowanie sposobu ustalania progu bankructwa. Może być on wyznaczany na podstawie potencjalnych wolnych przepływów finansowych (PFC), kosztów obsługi pożyczek na nieprzewidziane wydatki oraz wieku gospodarstwa domowego. Wielkość progu zmienia się w czasie. Ważnym elementem, który jest brany pod uwagę przy jego ustalaniu, są pożyczki na wypadek potrzeby finansowania nieprzewidzianych skumulowanych niedoborów finansowych oraz minimalna konieczna rata spłaty w danym okresie (zakładając, że oczekiwana dalsza długość życia w danym momencie jest traktowana jako maksymalny okres kredytowania). Minimalna konieczna płatność z tytułu pożyczek na nieprzewidziane wydatki w danym okresie nie może przekroczyć potencjalnej sumy wolnych przepływów pieniężnych przewidzianych na ten okres. Należy podkreślić, że wszystkie płatności wynikające z planowanych pożyczek są już z definicji uwzględnione w potencjalnym wolnym przepływie pieniężnym (równanie 8):

$$
P F C_{t}=I c_{t}-C_{\text {min }_{t}}+N I t_{t}+N D_{t}+C S p_{t}
$$


gdzie:

$I c_{t}$ - dochód w momencie $t$

$C_{\text {min }_{t}}-$ minimalna konsumpcja w momencie $t$

$N I t_{t}$ - przepływ pieniężny netto z inwestycji w momencie $t$

$N D_{t}$ - przepływ pieniężny netto z planowanych pożyczek w momencie $t$

Próg bankructwa w danym momencie jest taką wartością niedoboru finansowego, dla której koszt finansowania jest większy niż potencjalny wolny przepływ finansowy w kolejnym okresie.

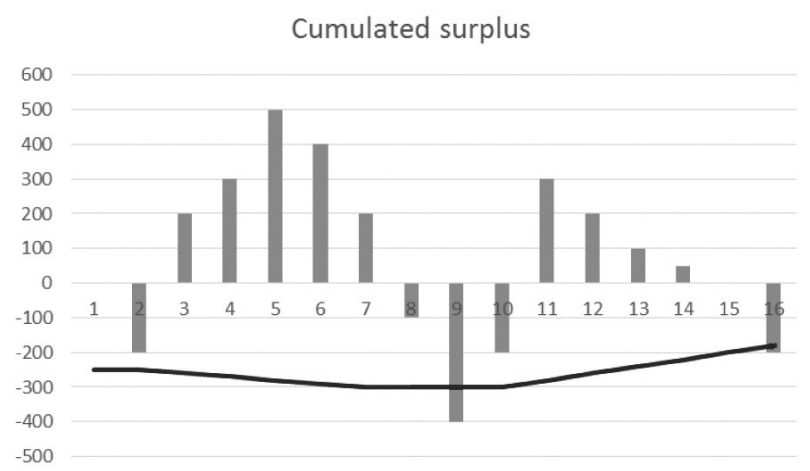

Rys. 1. Struktura terminowa skumulowanych przepływów finansowych (w wartościach realnych, modyfikowanych o wartość finansowania awaryjnego) z zaznaczonym progiem bankructwa (czarna linia)

Źródło: opracowanie własne.

Na rys. 1 przedstawiono przykład scenariusza, w którym występuje skumulowany niedobór środków finansowych w kilku momentach, a przekroczenie progu bankructwa następuje w momentach 9 i 16 . Oczywiście do potraktowania scenariusza jako scenariusza bankructwa wystarczy, że takie zdarzenie wystąpi tylko raz. Przedstawiona miara nie zawiera informacji o wielkości przekroczenia progu bankructwa ani o liczbie takich przekroczeń.

\section{Podsumowanie}

Wszystkie zaproponowane miary ryzyka są miarami zintegrowanymi. Oznacza to, że w swojej konstrukcji opierają się na pewnej całościowej informacji o potencjalnych wynikach planu finansowego gospodarstwa domowego. Wynikiem tym we wszystkich przypadkach jest wiązka ścieżek skumulowanego przepływu pieniężnego netto we wszystkich rozpatrywanych scenariuszach dla planu finansowego optymalizowanego przy warunkach brzegowych wymuszających realizację wszystkich celów finansowych gospodarstwa domowego i pewien minimalny akceptowalny poziom 
konsumpcji w całym cyklu życia tego gospodarstwa. Oznacza to, że w niektórych scenariuszach zostanie wygenerowany niedobór finansowy. Z kolei w niektórych spośród tych niekorzystnych scenariuszy niedobór ten będzie tak głęboki, że gospodarstwo domowe nie będzie w stanie z niego wyjść.

Podstawową kategorią finansową wykorzystywaną w konstrukcji miar ryzyka są skumulowane przepływy pieniężne netto. Niedobory finansowe - lub nawet dodatnie skumulowane przepływy, ale kształtujące się poniżej pewnego założonego poziomu - są naturalnym zagrożeniem dla realizacji planu finansowego. Jest tak bez względu na to, jaka konkretna kombinacja niekorzystnych wartości poszczególnych czynników ryzyka spowodowała niedobór finansowy lub wartość poniżej poziomu odniesienia. Dlatego można powiedzieć, że w przebiegu procesu skumulowanego przepływu pieniężnego netto znajduje odzwierciedlenie wpływ wszystkich czynników ryzyka, jakie zostały uwzględnione w modelu. Dzięki temu właśnie podejście oparte na skumulowanych przepływach pieniężnych netto jest dobrze dopasowane do zintegrowanego pomiaru ryzyka planu finansowego gospodarstwa domowego.

Zaprezentowane w niniejszym artykule propozycje mogą znaleźć zastosowanie zarówno na etapie oceny i wyboru planu, jak i jego rewizji. Wynikiem optymalizacji przy wskazanych przez gospodarstwo domowe ograniczeniach ( $\mathrm{w}$ tym przy założonych celach finansowych) może być bowiem plan, który będzie zrealizowany z sukcesem tylko w scenariuszu oczekiwanym i scenariuszach od niego korzystniejszych oraz tylko w bardzo nielicznych scenariuszach mniej korzystnych od oczekiwanego. Innymi słowy, będzie to plan o bardzo dużym ryzyku niepowodzenia. Taki plan może być nieakceptowalny ze względu na zbyt wysoki poziom ryzyka. Zaprezentowana koncepcja pomiaru ryzyka całego planu daje narzędzie oceny niedostępne $\mathrm{w}$ istniejącej literaturze. Pozwoli ono m.in. na usprawnienie procesu rewizji planu.

\section{Bibliografia}

Artzner P., Delbaen F., Eber J.-M., Heath D., Coherent measures of risk, "Mathematical Finance" 1999, Vol. 9(3), DOI: https://doi.org/10.1111/1467-9965.00068.

Bodie Z., Detemple J.B., Otruba S., Walter S., Optimal consumption-portfolio choices and retirement planning, "Journal of Economic Dynamics and Control" 2004, Vol. 28(6), DOI: https://doi.org/10.1016/ S0165-1889(03)00068-X.

Brown J.R., Poterba J.M., Joint life annuities and annuity demand by married couples, "Journal of Risk and Insurance" 2000, Vol. 67(4), DOI: https://doi.org/10.2307/253849.

Föllmer H., Schied A., Convex measures of risk and trading constraints, "Finance and Stochastics" 2002, Vol. 6(4), DOI: https://doi.org/10.1007/s007800200072.

Geyer A., Hanke M., Weissensteiner A., Life-cycle asset allocation and consumption using stochastic linear programming, "Journal of Computational Finance" 2009, Vol. 12(4).

Hurd M.D., Mortality Risk and Consumption by Couples, Working Paper, 1999, www.nber.org/papers/ w7048.pdf [dostęp: 10.12.2018].

Jajuga K., Feldman Ł., Pietrzyk R., Rokita P., Integrated Risk Model in Household Life Cycle, Publishing House of Wrocław University of Economics, Wrocław 2015. 
Kotlikoff L.J., Spivak A., The family as an incomplete annuities market, "Journal of Political Economy" 1981, Vol. 89(2), DOI: https://doi.org/10.1086/260970.

Markowitz H., Portfolio Selection: Efficient Diversification of Investments, John Wiley \& Sons, Inc., London 1959.

Merton R.C., Optimum consumption and portfolio rules in a continuous-time model, "Journal of Economic Theory" 1971, Vol. 3(4), DOI: https://doi.org/10.1016/0022-0531(71)90038-X.

Mitchell O.S., Bodie Z., Hammond B.P., Zeldes S. (eds.), Innovations in Retirement Financing, University of Pennsylvania Press, Philadelphia 2002.

Pietrzyk R., Rokita P., A decent measure of risk for a household life-long financial plan - postulates and properties, [w:] $34^{\text {th }}$ International Conference Mathematical Methods in Economics. Conference Proceedings, Technical University of Liberec, Liberec 2016a.

Pietrzyk R., Rokita P., Facilitating Household Financial Plan Optimization by Adjusting Time Range of Analysis to Life-Length Risk Aversion, [w:] A. Wilhelm, H.A. Kestler (eds.), Analysis of Large and Complex Data, Studies in Classification, Data Analysis, and Knowledge Organization, Springer International Publishing, Cham 2016b.

Pietrzyk R., Rokita P., On a concept of household financial plan optimization model, "Research Papers of Wrocław University of Economics" 2015a, No. 381.

Pietrzyk R., Rokita P., Stochastic goals in household financial planning for a two-person household, "Statistics in Transition. New Series" 2015b, Vol. 16(1).

Richard S.F., Optimal consumption, portfolio and life insurance rules for an uncertain lived individual in a continuous time model, "Journal of Financial Economics" 1975, No. 2.

Scholz J.K., Seshadri A., Health and Wealth In a Lifecycle Model, 2010, www.chicagofed.org/ /media/others/ research/research-calendar-attachments/seminars2010/sem-scholz051710-pdf.pdf [dostęp: 10.12.2018].

Yaari M.E., Uncertain lifetime, life insurance, and the theory of the consumer, "Review of Economic Studies" 1965, Vol. 32(2), DOI: https://doi.org/10.2307/2296058.

\section{Risk Measurement of Household Financial Plan}

When building a financial plan for a household, one usually needs to take many risk factors into account. These are the factors that have an influence on the shape of the future term structure of household incomes and expenditures. The factors may be of very differentiated nature, which means that their impact on the cash-flow term structure may be different both in terms of the underlying mechanism and strength. In this field of research, the existing literature does not provide, however, any proposals of integrated risk measurement. At the same time, the ability to measure risk of household financial plans in an integrated way would be very useful, as it would allow to select or compare plans with respect to the joint risk of a plan (to be more precise - the joint risk that the plan will fail to be successfully realized). The aim of this article is to propose a method or methods that would allow to measure financial plan risk in an integrated way. The integration should include different risk types, all financial goals that have been set by the household, all sources of financing and all sub-periods of the long-term life-cycle period of household financial planning. The approach, originally proposed by the authors of this article, may not only facilitate comparison of financial plans with respect to risk, but it may be also serve as a plan-acceptance decision-making instrument. Integrated risk measures may be also used within the very optimization procedure. They may be parts of the boundary conditions or even be embedded into the optimization function itself.

\section{Pomiar ryzyka planu finansowego gospodarstwa domowego}

Konstrukcja planu finansowego dla gospodarstwa domowego wymaga wzięcia pod uwagę wielu czynników ryzyka, które determinują kształtowanie przyszłej ścieżki dochodów i wydatków gospodarstwa domowego. Czynniki te mogą mieć bardzo różną naturę, a także bardzo zróżnicowany wpływ na strukturę 
Pobrane z czasopisma Annales H - Oeconomia http://oeconomia.annales.umcs.pl

Data: 26/04/2023 10:17:58

POMIAR RYZYKA PLANU FINANSOWEGO GOSPODARSTWA DOMOWEGO

przepływów finansowych. W literaturze brakuje jednak propozycji zintegrowanego pomiaru ryzyka, który umożliwiłby porównanie planów finansowych pod względem łącznego ryzyka ich realizacji. Celem artykułu jest zaproponowanie metod pomiaru ryzyka planu finansowego w sposób zintegrowany. W podejściu tym integracja powinna obejmować różne rodzaje ryzyka, wszystkie cele finansowe gospodarstwa domowego, wszystkie sposoby finansowania oraz wszystkie okresy w cyklu życia gospodarstwa domowego. Zaproponowane oryginalne podejście pozwala nie tylko na porównanie planów finansowych między sobą ze względu na poziom ryzyka, ale również tworzy narzędzie do podejmowania decyzji o akceptacji planu. Zintegrowane miary ryzyka mogą też być wykorzystane w samym procesie optymalizacji. Poza tym mogą stanowić ograniczenie lub wręcz element funkcji celu w procedurze optymalizacyjnej. 